IZA DP No. 7758

Subjective Evaluations:

Discretionary Bonuses and Feedback Credibility

William Fuchs

November 2013 


\title{
Subjective Evaluations: Discretionary Bonuses and Feedback Credibility
}

\author{
William Fuchs \\ University of California, Berkeley \\ and IZA
}

Discussion Paper No. 7758

November 2013

\author{
IZA \\ P.O. Box 7240 \\ 53072 Bonn \\ Germany \\ Phone: +49-228-3894-0 \\ Fax: +49-228-3894-180 \\ E-mail: iza@iza.org
}

\begin{abstract}
Any opinions expressed here are those of the author(s) and not those of IZA. Research published in this series may include views on policy, but the institute itself takes no institutional policy positions. The IZA research network is committed to the IZA Guiding Principles of Research Integrity.

The Institute for the Study of Labor (IZA) in Bonn is a local and virtual international research center and a place of communication between science, politics and business. IZA is an independent nonprofit organization supported by Deutsche Post Foundation. The center is associated with the University of Bonn and offers a stimulating research environment through its international network, workshops and conferences, data service, project support, research visits and doctoral program. IZA engages in (i) original and internationally competitive research in all fields of labor economics, (ii) development of policy concepts, and (iii) dissemination of research results and concepts to the interested public.
\end{abstract}

IZA Discussion Papers often represent preliminary work and are circulated to encourage discussion. Citation of such a paper should account for its provisional character. A revised version may be available directly from the author. 
IZA Discussion Paper No. 7758

November 2013

\section{ABSTRACT \\ Subjective Evaluations: \\ Discretionary Bonuses and Feedback Credibility ${ }^{*}$}

We provide a new rationale for the use of discretionary bonuses. In a setting with unknown match qualities between a worker and a firm and subjective evaluations by the principal, bonuses are useful in order to make the feedback from the firm to the workers credible. This way workers in good matches are less inclined to accept outside offers.

JEL Classification: D82, D83, D86, M5

Keywords: discretionary bonuses, feedback, signalling

Corresponding author:

William Fuchs

Haas School of Business

University of California Berkeley

545 Student Services Building

Berkeley, CA 94720-1900

USA

E-mail:wfuchs@haas.berkeley.edu

\footnotetext{
* An earlier version of this paper was titled "Subjective Evaluations: The Bonus as a Signal of Performance." It is based on my dissertation work at Stanford GSB. Special thanks are owed to Andy Skrzypacz, Tom Sargent, Ed Lazear and Jon Levin. I also benefited from comments by Simon Board, Ben Hermalin, John Morgan, Aniko Ory, Paul Oyer, Alessandro Pavan and Pablo Spiller. Support from the Ayacucho Fellowship and the National Science Foundation is gratefully acknowledged.
} 


\section{Introduction}

Why do we see bonus pay? ${ }^{1}$ The literature has mainly focused on two main answers to this question: 1) as a result of moral hazard on the agent's side, contingent pay is needed to motivate the worker to exert effort; 2) the agent, typically a CEO, has private information about his fit for the job and accepts contingent pay as a way to signal he is a good match for the task. Neither of these models provide a good explanation for why employees who neither produce a clear measurable output nor are in top management positions should receive contingent pay.

In this short paper, we propose a different explanation that applies to agents further down in the firm's hierarchy and whose output cannot be easily and objectively measured. In such environments, it is natural for the agent to be unaware of how well her superiors believe she is performing. The principal pays the agent a bonus conditional on good performance to signal to the agent that she is indeed a good fit for her job and has a bright future with her current employer. The bonus is not used to motivate the agent's effort or to have productive agents ex-ante self-select into the job, but rather its role is to make the principal's feedback credible.

To illustrate the problem, think of a business analyst at a consulting firm or a junior investment banker. These workers do not produce an easy to measure product. Moreover, they have little and hard to measure impact on the bottom line of the consulting firm or bank. Furthermore, it would be hard to argue that, in their case, accepting contingent pay is a way for them to signal something to their employers. On the contrary, partners in the firm can see the analysts working and soon form an opinion on their long run potential with the firm. In addition, a main concern of employees in these jobs is to determine their likelihood of making it to partner, that is the big carrot motivating long hours and weekends working hard. Many of these talented individuals receive outside offers from industry. Such offers are typically seen as a lower effort lower pay alternatives, but preferable if, indeed, one would not make it to the top. If the partners in the firm were not making any rents (or quasi-rents) out of their junior employees, then they would be indifferent about whether those employees stayed or took an outside offer. Hence, they would be happy to truthfully reveal to them their prospects in the company and see the less promising ones leave. On the other hand, if rents or quasi rents are being captured by the partners, then they would have incentives to hold on to their employees, even the less promising ones, for longer and would give all of them positive feedback and false hopes of their prospects of success in the firm. Employees would then forgo most of their outside options. Clearly, if the employees are aware of the partners behavior, this cannot be an equilibrium: they would not believe the feedback and would indeed be more receptive to outside offers.

The partners are not interested in having their talent fishing for outside options and hence would be interested in making their feedback credible. ${ }^{2}$ Discretionary bonuses, raises or anticipated promotions allow them to do exactly that. By putting their money where their mouth is they can credibly signal to the junior employees their prospects with the company and convince those that are a better fit not to leave the firm. We could also think of the first period as the interview phase and the bonus as a sign in bonus. Again, the

\footnotetext{
${ }^{1}$ Although I refer to bonus pay this stands in general for discretionary contingent pay. For example the bonus can be rolled over into next period's wage.

${ }^{2}$ In contrast, Oyer (2004) and Oyer and Schaefer (2005) analyze the use of option grants as a way to have agents receive higher compensation in states where the outside options are likely to be higher. Importantly, these contingent payments are not ex-post discretionary and are simply used to make the compensation adjustable to the overall market and do not convey any match specific information.
} 
firm is using the sign in bonus as a way to credibly convey to the prospective worker that she would have a bright future with the firm if she were to join. ${ }^{3}$

\section{Literature Review}

Starting with Harris and Raviv (1979), Holmstrom (1979) and Shavell (1979) there has been a huge literature based on the idea that, with an unobservable costly effort decision by the agent, the principal uses a bonus or some form of contingent pay based on the observable output to incentivice the agent to exert effort. By exerting effort, the worker can increase the likelihood of a high output realization and a higher compensation as a result. As discussed in Prendergast (1999), this theory has been quite successful at explaining the effect of the use of bonuses for tree planters (Paarsch and Shearer 1996) and windshield installers (Lazear 1996) among others. Yet the important distinction is that all of the examples share the fact that they tend to be simple tasks with easily measurable and verifiable output. ${ }^{4},{ }^{5}$

Incentive pay also has sorting effects because more productive agents would prefer a piece rate agreement than a fixed wage. The paper on windshield installers by Lazear (1996) neatly separates the incentive versus sorting effects. In later work, Lazear (2005) reviews the empirical literature and suggests that, particularly when thinking about CEOs, the use of variable compensation appears to be better explained by an adverse selection model where the CEOs accept variable compensation to signal that they are a good fit to run the company.

The rational for contingent pay proposed in this paper is also based on an asymmetric information story, but the key difference is that we assume that the principal is more informed than the agent. We model this by assuming the principal observes the agent's performance and forms a subjective and hence private opinion on how good a fit the agent is with the firm. In this respect, our paper is related to MacLeod (2003) Levin (2003) and Fuchs (2007). Although these papers and others that have followed all assume that there is a moral hazard problem on the side of the agent. ${ }^{6}$ In addition, Fuchs (2007) showed that in such an environment it is optimal for the principal not to provide feedback. In recent work Suvorov and van de Ven (2009) show that in the presence of moral hazard there can still be a role for feedback if the agent is intrinsically motivated to put effort only if he thinks the likelyhood of success is high. Zabojnik (2013) studies the role of feedback in fine tuning the agent's effort choice in a multitasking setting. ${ }^{7}$

In the present paper we show that when the outside options are potentially attractive the principal is better off providing feedback. An agent that receives positive feedback, will regard his future with the firm more promising and hence have a higher threshold on the outside offers it is willing to accept. If the principal is making money by having even the less promising agents around it would be tempted to give all agents positive feedback. Therefore, bonuses are needed in order to guarantee that the principal provides truthful feedback. The fact that there are different match qualities combined with the principal having

\footnotetext{
${ }^{3}$ Sign in bonuses in a setting with contractible output are studied in Van Wesep (2010). Although, it is hard in his setting to justify why firms would use sign in bonuses rather than commiting to higher wages and the equilibrium he characterizes in which they are used is not robust to small pertubations in the signal structure.

${ }^{4}$ See also MacLeod and Daniel Parent (1999).

${ }^{5}$ Even if output is not verifiable but common knowledge, then discretionary bonuses can be used to provide incentives in repeated relationships - see Bull (1987) and MacLeod and Malcomson (1989).

${ }^{6}$ See for example Maestri (2012).

${ }^{7}$ Note that the first draft of this paper predates both of these independent works and the idea that differing match qualities provides a rationale for feedback is referenced in Fuchs (2007): "Fuchs (2005) studies an environment in which there are different and unknown ex-ante match qualities in which communication has a role."
} 
private information about the outcome leads to a signaling game between the informed principal and the uninformed agent. The "types" of principal are given by the output the principal observed the first period. There is a single crossing property given by the fact that a principal that observed high output has a higher valuation for the agent because he has a higher belief of the match quality. If the principal has incentives to retain the agent then simple feedback (cheap talk) would not be credible. In this cases, by paying a bonus, the principal can put his money where his mouth is and thereby make the feedback credible. ${ }^{8}$

Note, that unlike the informed principal literature or Benabou and Tirole (2003), at the time of contracting the principal has no private information. In addition, the private evaluations limit the possibility of writing enforceable contracts. In an informed principal setting with contractible output Beaudry (1994) shows that a principal that values effort highly chooses to induce effort with a high base wage and low bonus payments and argues that therefore the informed principal setting can be used to explain the use of efficiency wages.

The notion of employee-firm specific match qualities that are gradually learnt over time dates back to Jovanovic (1979). In his paper it is essentially assumed that the firms pay the workers their expected marginal product every period. ${ }^{9}$ This could be sustained as an equilibrium only if output is common knowledge and might even require that it be contractible if the players are not sufficiently patient. We show that compensation will respond to expected output but it won't necessary be equal to the expected output. We still share the empirically consistent implications from Jovanovic (1979), namely that turnover decreases with tenure and higher pay. Since only few professions have contractible measures of output a model that does not require that has a more general applicability. In addition, my model suggests that the fraction of discretionary pay would be particularly relevant in predicting future separations providing a possible avenue to distinguish between both models. ${ }^{10}$

\section{The Model:}

The model is intentionally stripped down to a simple two period model in order to make the point in as clean and transparent a way as possible.

We have a worker (analyst) matched with a firm (partner). The quality/productivity of their match is assumed to be unknown. The productivity denoted by $\theta$ can either be high or low $\theta=\{L . H\}$. At time zero both agents share a common belief that the match is $H$ with probability $p$. While the analyst works for him, the partner privately observes the non-contractible output realizations $y \in\{l, h\}$. We will denote by $P(y=h \mid \theta)$ the probability of $y=h$ conditional on the agent's type and assume $1>P(y=h \mid \theta=H)>$ $P(y=h \mid \theta=L)>0$. Note that there are no moral hazard considerations, the agent produces the output without a choice of costly and hidden effort. ${ }^{11}$ The partner updates his beliefs on the quality of the match based on the output realization. We denote the partner's beliefs after observing the first output realization by $\lambda_{1}(y)$ and after the second by $\lambda_{2}\left(\lambda_{1}, y\right)$. By Bayes rule:

$$
\lambda_{1}(H)=\frac{p \times P(y=h \mid \theta=H)}{p \times P(y=h \mid \theta=H)+(1-p) P(y=h \mid \theta=L)}
$$

\footnotetext{
${ }^{8}$ This type of behavior is related to the study of leadership by Hermalin (1998). He argues that leaders have superior information and a temptation to mislead their followers. In order for the leader to credibly signal his private information he must then either sacrifice or set an example (a costly action).

${ }^{9}$ See the discussion of Jovanic's model in Ljungqvist and Sargent (2004)

${ }^{10}$ I thank Jan Zabojnik for this suggestion.

${ }^{11}$ The model can be generalized to account for a hidden effort choice but the results become less transparent.
} 


$$
\begin{gathered}
\lambda_{1}(L)=\frac{p \times(1-P(y=h \mid \theta=H))}{p \times(1-P(y=h \mid \theta=H))+(1-p)(1-P(y=h \mid \theta=L))} \\
\lambda_{2}\left(\lambda_{1}(.), H\right)=\frac{\lambda_{1}(.) \times P(y=h \mid \theta=H)}{\lambda_{1}(.) \times P(y=h \mid \theta=H)+\left(1-\lambda_{1}(.)\right) P(y=h \mid \theta=L)}
\end{gathered}
$$

At the end of the first period the employer can give some (verbal) feedback $f \in\left\{\emptyset, y_{l}, y_{h}\right\}$ to the worker. Where $\emptyset$ stands for the choice of the partner to give no feedback. The partner can also pay a bonus $b(f, y) \geq 0$ to the analyst. The partner also pays the first period's predetermined base wage $w_{1}$ and could also determine a different base wage $w_{2}$ for the second period but any difference in base wages can be subsumed into the bonus. So without loss of generality we will set $w_{2}=w_{1}=w$. Moreover, since $w$ doesn't play any role we will set $w=0$ alternatively we could argue that this is the wage level that makes the individual rationality constraint hold with equality.

The analyst has beliefs $\mu(f, b)$ after observing the principal feedback and bonus, that the quality of the match is $H$. Where possible, beliefs will be updated according to Bayes rule. ${ }^{12}$

At the beginning of the second period the analyst receives a random outside job offer $R_{1}$ distributed according to $G\left(R_{1}\right)$ she can either quit and receive $R_{1}$ or stay in the firm. If she stays, then there is the second output realization (only observable to the partner). The partner then determines if he fires the analyst or offers her a long term contract for wage $W .{ }^{13}$ If instead the agent gets fired she gets $R_{2}<W$. We denote by $T(\theta, W)$ the terminal value for the principal of hiring an agent of type $\theta$ for an exogenously fixed wage $W .^{14}$ The role of $\theta$ is to make the employer's problem non-trivial, by having $T(L, W)<0$ and $T(H, W)>0$. Let $\lambda^{*}$ be the belief that makes the expectation $E[T(\theta, W)]=0$. We will assume that $\lambda_{2}\left(\lambda_{1}(H), H\right) \geq \lambda^{*}>\max \left\{\lambda_{2}\left(\lambda_{1}(L), H\right), \lambda_{2}\left(\lambda_{1}(H), L\right)\right\}$ so that the partner will want to promote the analyst only if he observes two good outcomes.

A strategy for the analyst in this environment is simply given by a cutoff rule $R^{q}(f, b)$ which determines the minimal outside offer $R^{q}$ that she would be willing to accept (and hence quit) when receiving feedback $f$ and bonus $b$. For the partner, a strategy is composed of the feedback rule, the choice of bonus and the decision to make the agent a partner or not. Both agent and principal are risk neutral and for simplicity we will assume that they do not discount future payoffs.

\section{Equilibrium of the game}

This game potentially allows for two types of pure strategy equilibria. The first are separating equilibria in which the principal truthfully reveals to the agent the first period output realization. The second is a pooling equilibrium in which the manager gives no feedback to the agent. In this section we characterize both type of equilibria. Then we use the Intuitive Criterion to refine away all but one separating equilibrium.

\footnotetext{
${ }^{12}$ The results are robust to the case in which in addition the agent receives a private signal about the match quality. If this signal is very informative then there is less need for the principal to provide feedback. As long as the signal is weak the role for feedback will remain.

${ }^{13}$ Here $W$ stands for the present expected value to the agent being made a partner.

${ }^{14} W$ could be endogenized without affecting our results. It is reasonable to take $W$ as given since in many organizations there are standard contract that apply to many employees simulataneously. At UC Haas for example as a result of negotiations with the central campus there are strict guidelines on wages for faculty that get tenured.
} 


\subsection{Separating equilibria}

Consider the following strategy pair. The principal observes $y$. If $y=h$ he gives good feedback $f=$ $y_{h}$ otherwise he gives bad feedback $f=y_{l} \cdot{ }^{15}$ Only high outcome realizations and positive feedback is also accompanied by a bonus i.e. $b\left(y_{h}, H\right)=b>0, b\left(\{f, y\} \neq y_{h}, H\right)=0$. The agent at the beginning of the second period quits iff the outside option is higher than his reservation value i.e. if $R_{1}>R^{q}(f, b)$. Finally, the partner tenures the worker if he observes both good outcomes and does not otherwise. This is a dominant strategy for the partner in the second period given the assumptions.

First, we analyze the agents strategy taking the Principal's one as given.

Even if the analyst believes she performed well in the first period there is a threshold value $\bar{R}$ for the outside option above which the agent resigns for sure:

$$
\begin{array}{r}
\bar{R}=\left(\lambda_{1}(H) * P(y=h \mid \theta=H)+\left(1-\lambda_{1}(H)\right) P(y=h \mid \theta=L)\right) W+ \\
\quad\left(1-\left(\lambda_{1}(H) * P(y=h \mid \theta=H)+\left(1-\lambda_{1}(H)\right) P(y=h \mid \theta=L)\right)\right) R_{2}
\end{array}
$$

If the analyst does not get good feedback and either the equilibrium bonus $b$ or larger she believes that the first period output was low. Hence, the threshold value $R^{L}$ above which she receives anything other than good feedback and a bonus of $b$ or more is given simply by the expected value of the outside offer she would get at the end of the next period, $R_{2}$. That is,

$$
R^{L}=R_{2}
$$

If the analyst is following such a strategy, the only way to guarantee the partner will wish to give truthful feedback is if he weakly prefers to be honest. Hence, we must check that he does not prefer to say low when high or vice-versa. The range in which the bonus can lay is bounded from below by the minimal amount such that the principal that saw a low outcome would prefer to say so and pay no bonus rather than pretending to be the other type and paying a bonus.

$$
b \geq \underline{\mathrm{b}}=\left(G(\bar{R})-G\left(R^{L}\right)\right) \times\left[\begin{array}{c}
\left(\lambda_{1}(L) P(y=h \mid \theta=H)+\left(1-\lambda_{1}(L)\right) P(y=h \mid \theta=L)\right) h \\
+\left(1-\left(\lambda_{1}(L) P(y=h \mid \theta=H)+\left(1-\lambda_{1}(L)\right) P(y=h \mid \theta=L)\right)\right) l
\end{array}\right]
$$

On the other hand there is an upper bound on how much bonus the firm is willing to give to convince the agent. Above this bound the principal would always prefer to declare it observed a low outcome realization.

$b \leq \bar{b}=\left(G(\bar{R})-G\left(R^{L}\right)\right) \times\left[\begin{array}{c}\left(\lambda_{1}(H) P(y=h \mid \theta=H)+\left(1-\lambda_{1}(H)\right) P(y=h \mid \theta=L)\right)\left(h+T\left(\lambda_{2}, W\right)\right) \\ +\left(1-\left(\lambda_{1}(H) P(y=h \mid \theta=H)+\left(1-\lambda_{1}(H)\right) P(y=h \mid \theta=L)\right)\right) l\end{array}\right]$

Since $\lambda_{1}(H)>\lambda_{1}(L)$ it can be easily shown that (2) is always greater than (1) therefore the separating equilibrium always exists. We can use the Cho-Kreps (1987) Intuitive Criterion to eliminate all separating equilibria except the one where $b=\underline{\mathrm{b}}$. The lowest cost separating equilibrium selected by the intuitive criterion would also be the equilibrium of a game in which the firm chooses/commits ex-ante to the bonus

\footnotetext{
${ }^{15}$ There is an equivalent equilibrium where signals are known to be sent always in reverse but we will disregard it in the analysis since it is essentially a normalization of the language.
} 
amount but retains the discretion of granting it or not. ${ }^{16,17}$ Since it might be natural to think that the distribution of outside options varies over the business cycle. Our model would suggest that those outside influences would show up in the choices of discretionary compensation. ${ }^{18}$

\subsubsection{When will a pat in the back suffice?}

In the characterization above note that in general it is not required that in the equilibrium with the smallest bonus the bonus $\underline{b}$ must be strictly positive. We could have equilibria where the principal can reveal the output realization truthfully to the agent without needing a strictly positive bonus to make it credible. What is required for that is that the partner not be making any rents on the less productive analysts.

\subsection{Pooling Equilibrium}

Consider the case in which the strategy by the partner is to provide no feedback $f=\emptyset$ and pay a bonus $b_{p}$ regardless of what output he observed. The agent retains his prior if he observes $f=\emptyset$ and $b \geq b_{p}$ and believes $y=0$ otherwise.

The threshold value for the outside option above which the uninformed agent resigns is:

$$
\begin{aligned}
& R^{p}=(p * P(y=h \mid \theta=H)+(1-p) P(y=h \mid \theta=L))^{2} W+ \\
& \quad\left(1-(p * P(y=h \mid \theta=H)+(1-p) P(y=h \mid \theta=L))^{2}\right) R_{2}
\end{aligned}
$$

We will be using the intuitive criterion to refine away these equilibria.

The principal that observed $y=H$ is willing to pay up to $\Delta_{b}$ more than $b_{p}$ if that would convince the agent that $y=H$.

$$
\Delta_{b}=\left(G\left(R^{q}\right)-G\left(R^{p}\right)\right)\left(\begin{array}{c}
\left(\lambda_{1}(H) P(y=h \mid \theta=H)+\left(1-\lambda_{1}(H)\right) P(y=h \mid \theta=L)\right)\left(h+T\left(\lambda_{2}, W\right)\right) \\
+\left(1-\left(\lambda_{1}(H) P(y=h \mid \theta=H)+\left(1-\lambda_{1}(H)\right) P(y=h \mid \theta=L)\right)\right) l
\end{array}\right)
$$

On the other hand the value from deceiving the agent into believing the high outcome was observed for the principal that observed $y=l$ is only:

$$
v=\left(G\left(R^{q}\right)-G\left(R^{p}\right)\right)\left(\begin{array}{c}
\left(\lambda_{1}(L) P(y=h \mid \theta=H)+\left(1-\lambda_{1}(L)\right) P(y=h \mid \theta=L)\right) h \\
+\left(1-\left(\lambda_{1}(L) P(y=h \mid \theta=H)+\left(1-\lambda_{1}(L)\right) P(y=h \mid \theta=L)\right)\right) l
\end{array}\right)
$$

Clearly $v<\Delta b$ hence there exists a small $\varepsilon>0$ such that by the intuitive criterion when a bonus of $b_{p}+\Delta b-\varepsilon$ is observed it can only have been in the interest of the principal that observed the high outcome to give that bonus. This implies that no pooling equilibria survive the intuitive criterion.

\footnotetext{
${ }^{16}$ I thank Simon Board for making this observation.

${ }^{17}$ This alternative interpretation is similar to the practice of up or out contracts. The role of up or out contracts though is quite different than that one highlighted in Kahn and Huberman (1988). In their case limiting the principal's options is necessary to achieve good outcomes. In our setting, though potentially useful, it is not necessary.

${ }^{18}$ The empircal implementation might be hard since one would need to control for business cycle effects within the firm or construct a joint model of how things change over the business cycle within the firm as well as outside.
} 


\subsection{Summary}

We summarize our findings above in the following Proposition:

Proposition 1 i) There exists a unique equilibrium satisfying the Intuitive Criterion Refinement.

ii)In this equilibrium the partner provides truthful feedback to the analyst and provides a bonus $\underline{b} \geq 0$ only upon success.

iii) $\underline{b}$ must be strictly positive iff the partner would in expectation be making rents in the second period even on the analysts that had a poor performance in the first period.

\section{Concluding Remarks}

Although the model can be generalized in several directions, by stripping it down to its bare essentials the analysis above shows very transparently that contingent pay can play a distinct role to that traditionally analyzed in the literature. In addition to the potential for motivating effort or helping with the ex-ante selection we have showed that discretionary bonuses can help principals to credibly convey to their promising employees that they have a bright future with the company and hence convince them to forgo looking for outside options.

\section{References}

[1] Beaudry, P. (1994). Why an informed principal may leave rents to an agent. International Economic Review, 821-832

[2] Benabou, Roland, and Jean Tirole. 2003. "Intrinsic and Extrinsic Motivation." Review of Economic Studies 70(3): 489-520.

[3] Bengt Holmstrom, 1979. "Moral Hazard and Observability," Bell Journal of Economics, The RAND Corporation, vol. 10(1), pages 74-91, Spring.

[4] Cho, I-K. and David M Kreps, 1987 "Signaling games and stable equilibria". Quarterly Journal of Economics 102:179-221

[5] Fuchs,William.2004. "Subjective Evaluations: The Bonus as a Signal of Performance." Unpublished.

[6] Fuchs, William, 2007 "Contracting with Repeated Moral Hazard and Private Evaluations" American Economic Review, 200797 (4) pp

[7] Harris, Milton and Artur Raviv, 1979. "Optimal incentive contracts with imperfect information," Journal of Economic Theory, Elsevier, vol. 20(2), pages 231-259, April.

[8] Hermalin, Benjamin E. 1998. "Toward an Economic Theory of Leadership: Leading by Example" The American Economic Review, Vol. 88, No. 5 (Dec., 1998), pp. 1188-1206.

[9] Jovanovic, Boyan, 1979. "Job Matching and the Theory of Turnover". Journal of Political Economy, Vol.87 No.5, Part 1, (Oct.,1979), pp.972-990. 
[10] Kahn, Charles and Gur Huberman, 1988. "Two-Sided Uncertainty and "Up-or-Out" Contracts". Journal of Labor Economics, Vol. 6, No. 4 (Oct., 1988), pp. 423-444

[11] Lazear, Edward,.2005 "Output-Based Pay: Incentives or Sorting?" in Solomon W. Polachek, eds., Research in Labor Economics. Vol.23. Greenwich, CT: JAI Press, 2005, pp.1-25.

[12] Lazear, Edward,1996. "Performance Pay and Productivity," NBER Working Paper 5672.

[13] Levin, Jonathan. "Relational Incentive Contracts." American Economic Review, 2003, 93(3), pp. 835-57.

[14] MacLeod, W. Bentley. "Optimal Contracting with Subjective Evaluation." American Economic Review, 2003, 93(1), pp. 216-40.

[15] MacLeod, W. Bentley and Parent, Daniel. "Job Characteristics and the Form of Compensation," in SolomonW. Polachek, eds., Research in Labor Economics. Vol. 18. Greenwich, CT: JAI Press, 1999, pp.177-242.

[16] MacLeod, W. Bentley and Malcomson, James M. "Implicit Contracts, Incentive Compatibility,and Involuntary Unemployment." Econometrica, 1989, 57(2), pp. 447-80.

[17] Maestri, Lucas. 2012 "The Efficiency of Bonus-or-Terminate Incentive Schemes under Subjective Evaluations" Unpublished manuscrip.t

[18] Oyer Paul, 2004. "Why Do Firms Use Incentives That Have No Incentive Effects?" The Journal of Finance, 59, August 2004, 1619-1649

[19] Oyer Paul and Scott Schaefer, 2005. "Why Do Some Firms Give Stock Options To All Employees?: An Empirical Examination of Alternative Theories." Journal of Financial Economics, 76, April 2005, $99-133$

[20] Prendergast, Canice. "The Provision of Incentives in Firms." Journal of Economic Literature, 1999, $37(1)$, pp. 7-63.

[21] Shavell, Steven. "Risk Sharing and Incentives in the Principal and Agent Relationship." Bell Journal of Economics, 1979, 10(1), pp. 55-73.

[22] Suvorov, A. and van de Ven, J. "Discretionary rewards as a feedback mechanism."Games and Economic Behavior, Vol. 67 (2009), pp. 665-81.

[23] Van Wesep, Edward 2010. "Pay (Be)for(e) Performance: The Signing Bonus as an Incentive device" Review of Financial Studies, 2010

[24] Zabojnik, Jan 2013 "Subjective Evaluations with Performance Feedback" Forthcoming RAND Journal of Economics. 